\title{
Computed Tomography Colonography as a Sensible Option for Colorectal Cancer Screening: Evidence Based on Metanalysis
}

\section{Colonografia por tomografia computadorizada como uma opção sensível para o rastreamento do câncer colorretal: Evidências baseadas em metanálise}

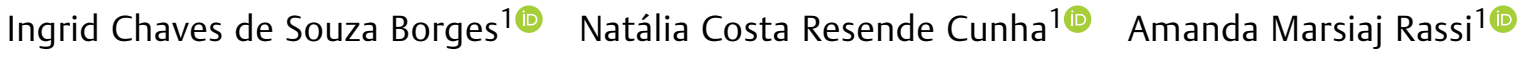 \\ Marcela Garcia de Oliveira ${ }^{10}$ Jacqueline Andréia Bernardes Leão-Cordeiro ${ }^{20}$ Fábio Silvestre Ataides ${ }^{10}$ \\ Rogério José Almeida10 Cesar Augusto Sam Tiago Vilanova-Costa30 \\ Antonio Márcio Teodoro Cordeiro Silva ${ }^{1,4}$
}

1 School of Medical, Biomedical and Pharmaceutical Sciences,

Pontifícia Universidade Católica de Goiás, Goiânia, GO, Brazil

Address for correspondence Antonio Márcio Teodoro Cordeiro Silva, MD, Escola de Ciências Médicas, Farmacêuticas e

2 Nursing School, Universidade Federal de Goiás, Goiânia, GO, Brazil

${ }^{3}$ Laboratory of Tumor Biology and Oncogenetics, Hospital Araújo Jorge,

Associação de Combate ao Câncer em Goiás, Goiânia, GO, Brazil

Biomédicas/Pontifícia Universidade Católica de Goiás, Avenida

Universitária 1.440, Setor Universitário, Campus 1, Área 4, Goiânia,

4 Postgraduate Program in Environmental Sciences and Health, Goiás, 74605-010, Brazil (e-mail: marciocmed@gmail.com).

Pontifícia Universidade Católica de Goiás, Goiânia, GO, Brazil

J Coloproctol 2021;41(1):87-95.
Abstract
Keywords
- virtual colonoscopy
- CT colonography
- optic colonoscopy
- colon cancer
- diagnosis

Objective This metanalysis aimed to evaluate the sensitivity and specificity of computed tomography colonography in colorectal polyp detection.

Methods A literature search was performed in the PubMed and Web of Science databases.

Results A total of 1,872 patients (males $57.2 \%$, females $42.8 \%$ ) aged 49 to 82 years old (mean age $59.7 \pm 5.3$ years) were included in this metanalysis. The estimated sensitivity of computed tomography colonography was $88.4 \%$ (46.3-95.7\%, coefficient of variation $[C V]=28.5 \%)$ and the estimated specificity was $73.6 \%(47.4-100.0 \%$, $\mathrm{CV}=37.5 \%)$. For lesions up to $9 \mathrm{~mm}$, the sensitivity was $82.5 \%(62.0-99.9 \%$, CV $=25.1 \%)$ and the specificity was $79.2 \%(32.0-98.0 \%, C V=22.9 \%)$. For lesions $>9 \mathrm{~mm}$, the sensitivity was $90.2 \%(64.0-100.0 \%, C V=7.4 \%)$ and the specificity was $94.7 \%$ $(80.0-100.0 \%, \quad C V=6.2 \%)$. No statistically significant differences in sensitivity received

June 3, 2020

accepted

August 8, 2020
DOI https://doi.org/

10.1055/s-0041-1726079. ISSN 2237-9363. (c) 2021. Sociedade Brasileira de Coloproctologia. All rights reserved.

This is an open access article published by Thieme under the terms of the Creative Commons Attribution-NonDerivative-NonCommercial-License, permitting copying and reproduction so long as the original work is given appropriate credit. Contents may not be used for commercial purposes, or adapted, remixed, transformed or built upon. (https://creativecommons.org/ licenses/by-nc-nd/4.0/)

Thieme Revinter Publicações Ltda., Rua do Matoso 170, Rio de Janeiro, RJ, CEP 20270-135, Brazil 


\section{Resumo}

\author{
Palavras-chave \\ - colonoscopia virtual \\ - colonografia por \\ tomografia \\ computadorizada \\ - colonoscopia ótica \\ - câncer colorretal \\ - diagnóstico
}

according to the size of the lesion were found ( $p=0.0958)$; however, the specificity was higher for lesions $>9 \mathrm{~mm}(p<0.0001)$.

Conclusions Most of the studies analyzed in the present work were conducted before 2010, which is about a decade after computed tomography colonography started being indicated as a screening method by European and American guidelines. Therefore, more studies aimed at analyzing the technique after further technological advancements are necessary, which could lead to the development of more modern devices.

Objetivo Esta meta-análise teve como objetivo avaliar a sensibilidade e especificidade da colonografia por tomografia computadorizada na detecção de pólipos colorretais. Métodos Foi realizada uma pesquisa bibliográfica nas bases de dados da PubMed e da Web of Science.

Resultados Um total de 1.872 pacientes, $57,2 \%$ homens e $42,8 \%$ mulheres, com idades entre 49 a 82 anos de idade (média de 59,7 $\pm 5,3$ anos) foram incluídos nesta meta análise. A sensibilidade da colonografia por tomografia computadorizada foi estimada em $88,4 \%$ (46,3-95,7\%; coeficiente de variância $[C V]=28,5 \%)$ e a especificidade em 73,6\% (47,4\%-100,0\%; CV =37,5\%). Para lesões de até $9 \mathrm{~mm}$, a sensibilidade foi de $82,5 \%(62,0-99,9 \% ; C V=25,1 \%)$ e a especificidade de $79,2 \%(32,0-98,0 \%$; $\mathrm{CV}=22,9 \%$ ). Para lesões maiores que $9 \mathrm{~mm}$, a sensibilidade foi de $90,2 \%(64,0-100,0 \%$; $C V=7,4 \%$ ) e a especificidade de $94,7 \%(80,0-100,0 \% ; C V=6,2 \%)$. Não houve diferença estatisticamente significante entre as sensibilidades por tamanho da lesão $(p=0,0958)$, porém a especificidade foi maior em lesões acima de $9 \mathrm{~mm}(p<0,0001)$. Conclusão A maioria dos estudos analisados no presente trabalho foi realizada antes de 2010 , cerca de uma década depois que a colonografia por tomografia computadorizada passou a ser indicada como método de triagem pelas diretrizes europeias e americanas. Portanto, são necessários mais estudos com o objetivo de analisar a técnica após maiores avanços tecnológicos, o que poderia levar ao desenvolvimento de dispositivos mais modernos.

\section{Introduction}

The number of cancer cases has been increasing exponentially, which could be attributed to technological advancements and lifestyle changes. The World Health Organization, through its International Agency for Research on Cancer, released the latest World Cancer Report (WCR) in 2014, which clearly showed that cancer is currently a serious public health problem (Stewart \& Wild, 2014). The WCR 2014 is the latest in a series of 3 reports on the global status of neoplastic diseases. The first, in 2003, estimated that 5.3 million men and 4.7 million women develop cancer annually. Eleven years thereafter, as described in the WCR 2014, the number of people living with cancer has increased to $\sim 14$ million per year. In addition, the report found that the number of new cases would likely increase worldwide by around 70\% in just 2 decades. $^{1}$

In Brazil, the number of cancer cases has become alarming. For the 2018 to 2019 biennium, 600,000 new cancer cases were estimated. In Goiás, Brazil, the same document estimated 17,810 new cases, which included all types of cancer. $^{2}$ Except for non-melanoma skin cancer, the most prevalent type of cancer in men is prostate cancer $(68,220$ new cases), followed by lung cancer (18,740 new cases), and colorectal cancer (17,380 new cases). In women, the most frequent types are breast cancer $(59,700$ new cases), colorectal cancer (18,980 new cases), and cervical cancer $(16,370$ new cases). ${ }^{2}$ Thus, colorectal cancer has a high incidence in both genders. In addition, this finding is also observed worldwide; according to the WCR 2014, colorectal cancer accounts to $\sim 10 \%$ of all cancers globally. Moreover, colorectal cancer is the fourth most common cause of cancer-related death worldwide. Therefore, this type of cancer has not only a high incidence but also a high mortality rate. ${ }^{1}$

Furthermore, the known etiological association of colorectal cancer with modern sedentary lifestyle and poor health habits, such as smoking, alcohol intake, and a poor diet, is also worrisome. A diet rich in calories, animal fat, and meats, together with physical inactivity, increases the chance of developing colorectal cancer. ${ }^{3}$ This could explain the fact that $>65 \%$ of new cancer cases occur in developed countries, where such lifestyle predominates. ${ }^{4}$

There are two main types of colorectal cancer precursor lesions that, if identified early, may prevent colorectal cancer: conventional adenomatous polyps and serrated lesions. Adenomas account for $70 \%$ of colorectal cancers and are 
classified as villous, tubular, and tubulovillous. Presumably, progression of these adenomas to carcinomas takes on average 10 years in people with moderate risk and 1 to 2 years in those with familial syndromes, such as Lynch syndrome. By definition, adenomas are dysplastic alterations, that is, tissue proliferation with loss of differentiation; adenomas with a high degree of dysplasia are considered advanced and are $>1 \mathrm{~cm}$ in size. ${ }^{5}$ Serrated lesions account for $\sim 30 \%$ of colorectal cancers and are classified as hyperplastic polyps without oncogenic potential or serrated polyps. They are histologically different, as they are rarely dysplastic; they have few vessels on their surface and tend to be flatter lesions. In addition, their distribution is more prevalent in the right colon and; thus, they are often underdiagnosed, with incomplete colonoscopies or sigmoidoscopies. ${ }^{5}$

Considering the epidemiological and evolutionary characteristics of the disease, early detection and removal of colorectal cancer precursor lesions could result in better outcomes and a significant reduction in the incidence and mortality of this type of cancer. Hence, new detection approaches have been developed, which promise better outcomes. The American Cancer Society (ACS) published its first screening recommendation in 1980. Subsequently, recommendations for moderate-risk individuals were provided in 2008, which were based on a consensus involving the ACS, the American College of Radiology, and the US Multi-Society Task Force on Colorectal Cancer (representing the American College of Gastroenterology, the American Gastroenterological Association, and the American Society for Gastrointestinal Endoscopy). In 2018, new recommendations were published, reinforcing the idea that screening and early detection of colorectal cancer should be an effort undertaken by individuals in the population and should be included in basic health care. ${ }^{6}$

According to the current recommendation, screening should be initiated preferably at the age of 45 years in those with a moderate risk of colorectal cancer using highly sensitive fecal tests or structural (visual) examinations. Moderaterisk individuals are those who have no history of adenomatous polyps or colorectal cancer; no increased risk for cancer either by family history or hereditary syndromes related to colorectal cancer, such as familial adenomatous polyposis or Lynch syndrome; no history of pelvic or abdominal radiation for a previous cancer; and no history of inflammatory bowel disease. Moreover, screening should be maintained in those aged 75 years who are in good health and have a life expectancy of $>10$ years and should be discontinued in those aged $\geq 85$ years. $^{6}$ In addition, according to the ACS recommendation, the following fecal screening tests should be considered: annual fecal immunochemical test, annual high-sensitivity guaiac-based fecal occult blood test, and fecal DNA test every 3 years. Among the structural (visual) examinations, colonoscopy should be performed every 10 years, computed tomography (CT) colonography every 5 years, and flexible sigmoidoscopy every 5 years. It is further recommended to perform these structural tests when fecal tests show unfavorable results. ${ }^{6}$

Conventional colonoscopy, or optic colonoscopy, remains the gold standard in evaluating colorectal cancer precursor lesions as biopsy could be performed when assessing suspicious alterations in the colonic mucosa. Nevertheless, new approaches have emerged that have aimed at increasing the number of people that adhere to the screening. Among these new approaches, CT colonography appears to be a sound choice and is one of the structural examinations for colorectal cancer screening since $2008 .^{6}$

Computed tomography colonography involves the acquisition of tomographic images that could be evaluated in two or three dimensions using specific software. The image is reconstructed to create a view that is similar to the image as seen using the optical colonoscope. However, it has disadvantages, such as radiation (which is claimed to be cancer inducing), difficulty in evaluating flat lesions, and the possibility of colonic perforation, which is common in conventional colonoscopy. Nonetheless, as an advantage, conventional colonoscopy does not require sedation and allows for extracolonic findings during the same examination. ${ }^{6}$

Therefore, the present study aimed to evaluate the sensitivity and specificity of CT colonography in the detection of colorectal polyps through a systematic review and metaanalysis.

\section{Methods}

The paper search and data collection were performed using a search protocol with the following criteria: subject interest, inclusion criteria, search strategy and data selection, data analysis, and result presentation and interpretation. Indexed papers from two available databases (PubMed and Web of Science), including textual descriptions, were analyzed using the Preferred Reporting Items for Systematic Reviews and Meta-Analyses (PRISMA) recommendations. We used the following terms to search in PubMed and Web of Science: screening AND virtual colonoscopy AND colorectal cancer. Only papers in English and published from November 2007 to November 2017 were included in the present study. References from revision papers and consensus were manually searched to ensure the inclusion of all relevant papers. No contact with clinical investigators to verify research in progress was made.

\section{Eligibility Criteria}

The inclusion criteria were as follows: (1) study evaluating the screening of a population with a medium risk of colorectal cancer, that is, those with colon polyps that were identified and biopsied by colonoscopy (which is the most accurate tool to diagnose colorectal neoplasia), including false-positive, false-negative, true-positive, and true-negative values; (2) studies that employed laxative preparation of the colon (without restriction of the type of laxatives) and that use stool tagging (24hour prior to preparation), fluid tagging (during the examination day), and subcutaneous glucagon, with or without venous contrast; (3) studies that used tomography for distended intestine due to ambient air or $\mathrm{CO}_{2}$, with images acquired in the supine and prone positions and with at least 16 tomographic cuts; and (4) studies that 
obtained 2D and 3D images that were analyzed using suitable software.

The exclusion criteria were as follows: (1) studies that did not compare the results of CT colonography with those of conventional colonoscopy; (2) studies that evaluated other variables (e.g., cost-benefit, patient acceptance, and types of laxative); (3) studies that sought to identify other abnormalities (e.g., intestinal obstruction, extracolonic findings, postoperative complications); and (4) studies that analyzed colorectal cancer that is not polyp-related, symptomatic patients (as this study's objective was to evaluate CT colonography as a screening method), or those with inflammatory bowel disease.

\section{Study Selection, Data Extraction, and Quality of Evidence}

Two researchers performed all the search process from localization to paper selection independently. Relevant data were extracted and differences resolved by consensus. Potentially eligible articles were obtained and read in full. A third researcher was involved to clarify any doubt about the inclusion of a particular paper.

Study quality was assessed using the Grading of Recommendations, Assessment, Development, and Evaluations (GRADE). ${ }^{7}$ The quality of evidence of the studies was classified into four categories: high, moderate, low, or very low. ${ }^{8}$ We also analyzed the influence of possible conflicts of interest and any information on ethical approval of the studies. $^{9}$

\section{Statistical Analysis}

Initially, heterogeneity of the studies, which could strongly affect the results and was defined as the diversity of the studies, was evaluated using the heterogeneity $x^{2}$ test. The results frequencies of all articles were grouped into a single table, and diversity was assessed using the heterogeneity $\mathrm{X}^{2}$ test in $2 \times 2$ contingency tables to compare the different odds ratios (ORs) with $95 \%$ confidence interval. ${ }^{10}$

A $p$-value $>0.05$ based on the heterogeneity $x^{2}$ test indicated that the null hypothesis was accepted, thereby confirming that the studies were homogeneous. Thus, we used the fixed-effect tests, which assumed that all studies point in the same direction. By contrast, a $p$-value $<0.05$ based on heterogeneity $\mathrm{X}^{2}$ test indicated diversity and heterogeneity of the studies. In this case, we used the random-effects test or random testing, such as the DerSimonian-Laird test. ${ }^{10}$

Moreover, global association tests were employed to assess the significance of the correlation between CT colonography and colorectal cancer diagnosis. To estimate the efficiency of CT colonography in colorectal cancer diagnosis, the values of the fixed- and random-effects tests from each study were combined and analyzed using BioEstat 5.0 (BioEstat, Belém, PA, Brazil). ${ }^{11}$

The ORs and 95\% confidence intervals of both the fixedeffect tests and random effects and the weight of the studies (individually and in combination) were calculated to obtain an estimated combined effect. Studies with increased statistical power, that is, those with larger populations and greater effect, have greater weight. In addition, the tests developed forest plot-type graphics. The charts summarize in the same space all information on the effect and the contribution of each study to the analysis. ${ }^{10}$

\section{Results}

Our literature search on PubMed yielded 830 articles, of which 761 were excluded after reading the title and abstract because of irrelevance. Of the remaining 69 articles, 5 were excluded as they were not written in Portuguese or English, and another 57 were excluded for not meeting the inclusion criteria. A total of 7 articles $^{12-18}$ that had all the necessary data were included in the analysis (-Fig. 1).

Most of the studies (85.7\%) were performed in Europe, where CT colonography is more advanced, and only one (14.3\%) was performed in the USA ( - Table 1 ). In addition, only one of the articles was published after the year 2010 , indicating that the progress of the research on CT colonography coincides with the time it was considered as a screening method. Data of a total of 1,872 patients were obtained, out of whom $57.2 \%$ were male and $42.8 \%$ were female. Their ages ranged from 49 to 82 years (mean 59.7 years \pm 5.3 years).

The estimated sensitivity of CT colonography for all studies was $88.4 \%$ (46.3-95.7\%, coefficient of variation [CV] $=28.5 \%$ ); (-Fig. 2). When grouped by lesion size, the data showed that the sensitivity was $82.5 \%$ (62.0-99.9\%, CV $=25.1 \%$ ) for lesions up to $9 \mathrm{~mm}$ and $90.2 \%$ (64.0-100.0\%, $\mathrm{CV}=7.4 \%$ ) for lesions $>9 \mathrm{~mm}$. Of the 7 articles, only 1 did not show data on polyps $>10 \mathrm{~mm}$ (-Table 2 ).

Regarding specificity (-Fig. 2), CT colonography had an overall specificity of $73.6 \%$ (47.4-100.0\%, CV $=37.5 \%$ ). For lesions up to $9 \mathrm{~mm}$, the specificity was $79.2 \%$ (32.0-98.0\%, $\mathrm{CV}=22.9 \%$ ); for lesions $>9 \mathrm{~mm}$, the specificity was $94.7 \%$ (80.0-100.0\%, CV $=6.2 \%)$. No differences in sensitivity according to lesion size were found $(p=0.0958)$; however, the specificity was higher for lesions $>9 \mathrm{~mm}(p<0.0001)$ (-Table 2).

No statistically significant difference in sensitivity was observed $(p=0.0958)$ when grouped by lesion size; an increase in lesion size did not increase the sensitivity of the test (-Table 3, - Fig. $\mathbf{3}$ ).

However, an increase in specificity $(p<0.0001)$ when grouped by lesion size was found. The chance of diagnosing lesions $>9 \mathrm{~mm}$ was 3 times greater than the chance of diagnosing lesions $\leq 9 \mathrm{~mm}$ (-Table 4, -Fig. 4).

\section{Discussion}

Colorectal cancer has a high global and national incidence and high mortality rates, and it is the fourth leading cause of cancer-related deaths. Thus, studies that could further our knowledge on accurate diagnostic methods are necessary to reduce negative outcomes. ${ }^{4}$ Fecal occult blood screening is a method currently used by the public health care system. However, despite having a relatively good sensitivity, it has a considerable number of false positives. Currently, 


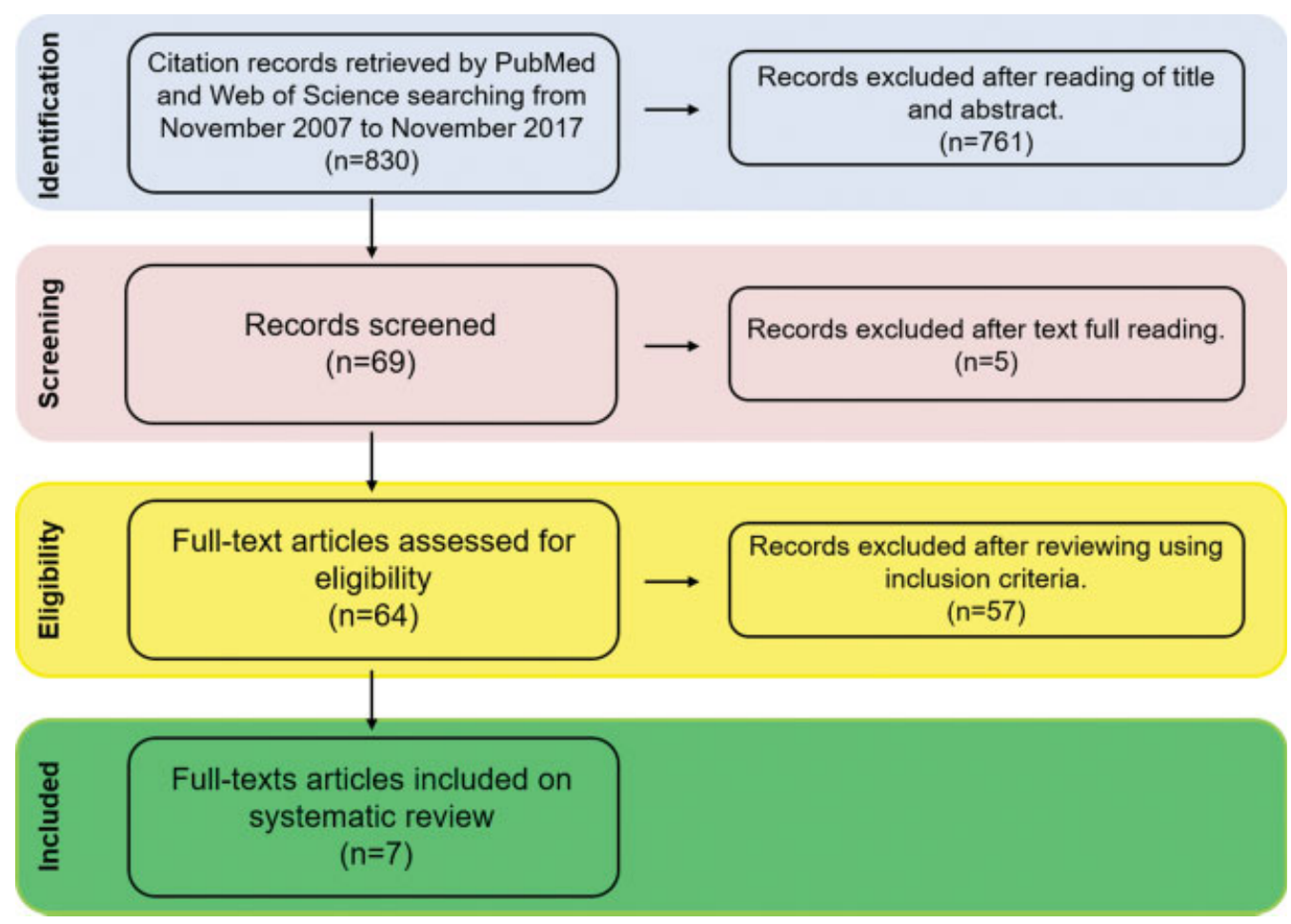

Fig. 1 Flow chart of the studies included in the metanalysis of the sensitivity and specificity evaluations of virtual colonoscopy.

colonoscopy is almost always the selected diagnostic test and is recommended only for high-risk patients or those with positive fecal occult blood tests, according to the public health care system. ${ }^{2}$

History of colorectal cancer reveals that $>80 \%$ of the cases result from the progression of an adenomatous polyp. Additionally, the adenoma-carcinoma progression occurs at a slow rate. On average, the progression of benign lesions to malignant lesions occurs in a period of 10 years, which is an ideal period for detection. ${ }^{2}$ Hence, more precise and faster diagnostic methods are beneficial. The present study aimed at evaluating the sensitivity of CT colonography as a diagnostic test and at understanding whether its use is advantageous or not for the reduction of the incidence and consequences of colorectal cancer worldwide.
Since its implementation in the 1990s, CT colonography has become a viable alternative to conventional colonoscopy (or optic colonoscopy) for the screening of colorectal cancer. It has the following advantages: examination without sedation; lower risk of complications compared with conventional colonoscopy, such as intestinal perforation during the examination; and better patient tolerance, thereby increasing patient adherence to the test. Moreover, with CT colonography, detecting extracolonic alterations in the abdominal or pelvic cavity is possible, which could in turn lead to new treatment approaches depending on the attending physician. ${ }^{19}$ Our study only analyzed the sensitivity and specificity of CT colonography and did not consider the risk of complications or patient acceptance.

Table 1 Absolute frequency and relative percentage by gender; total number of participants; minimum, maximum, and mean age; and standard deviation

\begin{tabular}{|c|c|c|c|c|c|c|c|c|c|c|c|}
\hline \multirow[t]{2}{*}{ Author } & \multirow[t]{2}{*}{ Year } & \multirow[t]{2}{*}{ Local } & \multicolumn{4}{|c|}{ Gender } & \multirow[t]{2}{*}{ Total } & \multicolumn{4}{|l|}{ Age } \\
\hline & & & $M$ & $F(\%)$ & $\mathrm{F}$ & $F(\%)$ & & Min & $\operatorname{Max}$ & Mean & SD \\
\hline Cornett & 2008 & USA & 81 & 50.9 & 78 & 49.1 & 159 & 49 & 82 & 59.3 & 3 \\
\hline Graser & 2009 & Germany & 171 & 55.0 & 140 & 45.0 & 311 & 50 & 81 & 60.5 & 7 \\
\hline Liedenbaum & 2009 & Netherlands & 187 & 61.9 & 115 & 38.1 & 302 & - & - & 61.0 & 6 \\
\hline Sali & 2010 & Italy & 30 & 61.2 & 19 & 38.8 & 49 & - & - & 60.5 & - \\
\hline Liedenbaum & 2010 & Netherlands & 187 & 61.9 & 115 & 38.1 & 302 & 50 & 75 & - & - \\
\hline Heresbach & 2011 & France & 131 & 51.8 & 122 & 48.2 & 253 & 50 & 67 & 57.2 & - \\
\hline Lefere & 2013 & Portugal & - & - & - & - & 496 & 50 & 75 & - & - \\
\hline Combined & & & 787 & 57.2 & 589 & 42.8 & 1872 & 49 & 82 & 59.7 & 5.3 \\
\hline
\end{tabular}

Abbreviations: F, female; M, male; Max, maximum; Min, minimum; SD, standard deviation. 
92 Computed Tomography Colonography for Colorectal Cancer Screening de Souza Borges et al.

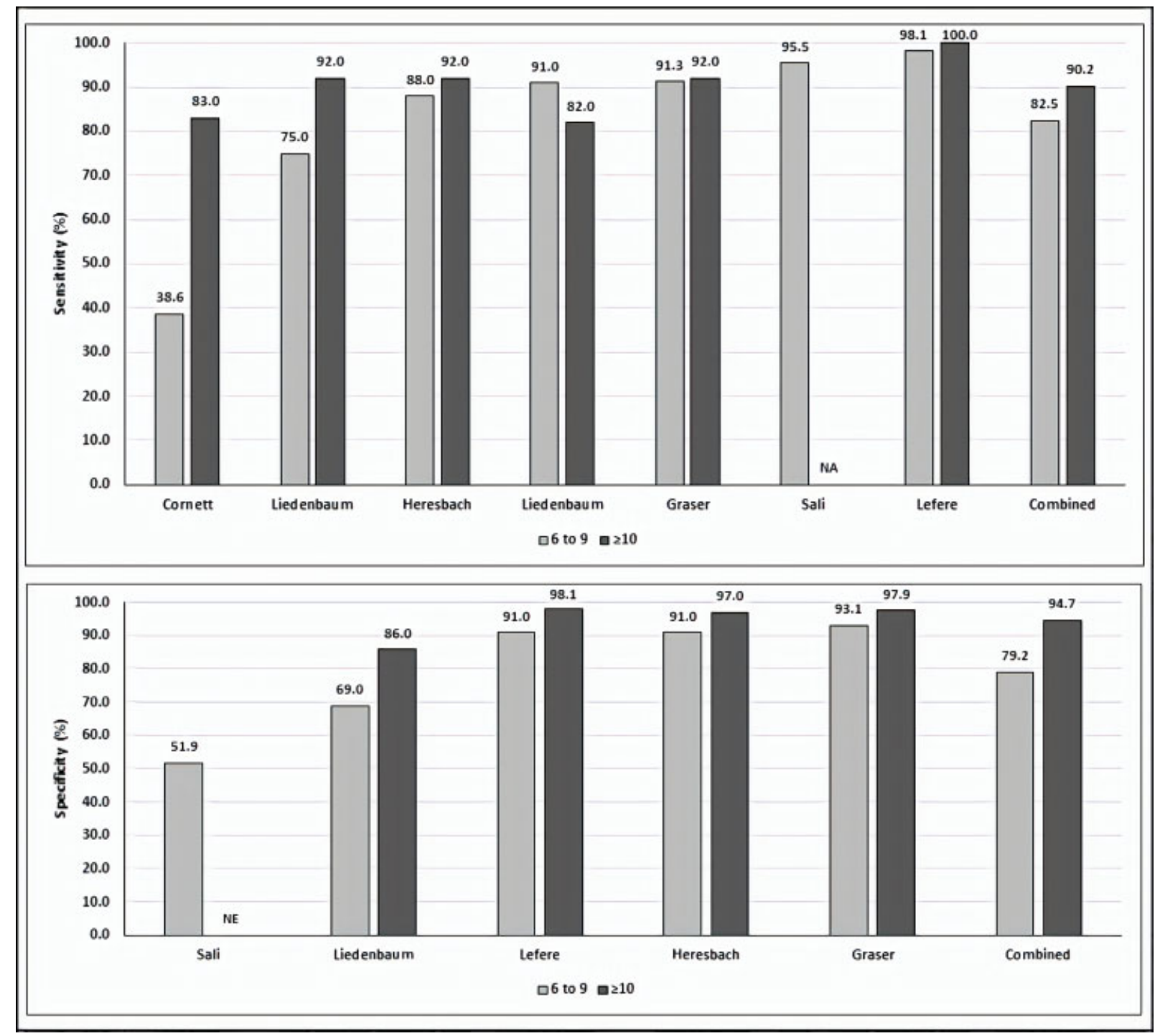

Fig. 2 Sensitivity and specificity of virtual colonoscopy grouped by lesion size.

The comparative analysis in our study showed that the sensitivity of CT colonography is similar to that of conventional colonoscopy for adenomas up to $9 \mathrm{~mm}$ (75-93\%) and those $>9 \mathrm{~mm}$ (89-98\%). However, the specificity of optic colonoscopy (94\%) is statistically higher than that of CT colonography for polyps below $<9 \mathrm{~mm}$. For larger polyps, the specificity of CT colonography and that of conventional colonoscopy are statistically close. ${ }^{6}$ Thus, for conventional colonoscopy, polyp size has less influence on screening efficiency as it relies on direct visualization of the lesion,

Table 2 Sensitivity and specificity of virtual colonoscopy grouped by lesion size

\begin{tabular}{|c|c|c|c|c|c|c|c|c|c|}
\hline \multirow[t]{2}{*}{ Author } & \multirow[t]{2}{*}{ Year } & \multicolumn{4}{|c|}{$6-9 \mathrm{~mm}$} & \multicolumn{4}{|c|}{$>9 \mathrm{~mm}$} \\
\hline & & Sens. & $95 \% \mathrm{Cl}$ & Spec. & $95 \% \mathrm{Cl}$ & Sens. & $95 \% \mathrm{Cl}$ & Spec. & $95 \% \mathrm{Cl}$ \\
\hline Cornett & 2008 & 38.6 & - & - & - & 83.0 & - & - & - \\
\hline Graser & 2009 & 91.3 & 79.2-97.6 & 93.1 & $89.3-95.9$ & 92.0 & $74.0-99.0$ & 97.9 & $95.4-99.2$ \\
\hline Liedenbaum & 2009 & 91.0 & $85.0-91.0$ & 69.0 & $60.0-89.0$ & 82.0 & $74.0-89.0$ & 86.0 & $80.0-93.0$ \\
\hline Sali & 2010 & 95.5 & $77.2-99.9$ & 51.9 & $32.0-71.3$ & - & - & - & - \\
\hline Liedenbaum & 2010 & 75.0 & $69.0-81.0$ & - & - & 92.0 & $88.0-96.0$ & - & - \\
\hline Heresbach & 2011 & 88.0 & $62.0-98.0$ & 91.0 & $76.0-98.0$ & 92.0 & $64.0-100.0$ & 97.0 & $86.0-100.0$ \\
\hline Lefere & 2013 & 98.1 & 88.6-99.9 & 91.0 & $87.8-93.4$ & 100.0 & $84.0-100.0$ & 98.1 & $96.3-99.0$ \\
\hline Combined & & 82.5 & $62.0-99.9$ & 79.2 & $32.0-98.0$ & 90.2 & $64.0-100.0$ & 94.7 & $80.0-100.0$ \\
\hline
\end{tabular}

Abbreviations: Sens., sensitivity; Spec., specificity; $\mathrm{Cl}$, confidence interval. 
Table 3 Calculation of the odds ratio, 95\% confidence interval, and weight of each study and of the studies combined for the sensitivity of virtual colonoscopy grouped by lesion size

\begin{tabular}{|c|c|c|c|c|c|c|c|}
\hline \multirow[t]{2}{*}{ Author } & \multirow[t]{2}{*}{ Year } & \multicolumn{2}{|c|}{ Sensitivity } & \multirow[t]{2}{*}{ OR } & \multicolumn{2}{|l|}{$95 \% \mathrm{Cl}$} & \multirow[t]{2}{*}{ Weight } \\
\hline & & $\leq 9 \mathrm{~mm}$ & $>9 \mathrm{~mm}$ & & Lower & Upper & \\
\hline Cornett & 2008 & 38.6 & 83.0 & 7.744 & 6.289 & 9.537 & 88.62 \\
\hline Graser & 2009 & 91.3 & 92.0 & 1.095 & 0.798 & 1.503 & 38.41 \\
\hline Liedenbaum & 2009 & 91.0 & 82.0 & 0.452 & 0.345 & 0.592 & 52.10 \\
\hline Liedenbaum & 2010 & 75.0 & 92.0 & 3.817 & 2.917 & 4.995 & 53.10 \\
\hline Heresbach & 2011 & 88.0 & 92.0 & 1.565 & 1.163 & 2.106 & 43.59 \\
\hline Lefere & 2013 & 98.1 & 100.0 & 39.755 & 2.345 & 659.371 & 0.49 \\
\hline Combined & & 80.3 & 90.2 & 2.372 & 0.858 & 6.553 & $p=0.0958$ \\
\hline
\end{tabular}

Abbreviations: $\mathrm{Cl}$, confidence interval; $\mathrm{OR}$, odds ratio.

which minimizes the interference of fluids, feces, or intestinal anatomy alterations.

Our study was in agreement with other similar studies. For example, a previous large metanalysis showed a sensitivity CT colonography ranging from 86 to $96 \%$ for adenomas $>6 \mathrm{~mm} .{ }^{20}$ Thus, CT colonography is a reliable option when optic colonoscopy is not available or for patients who would not prefer the conventional method. Confidence in this method, even for small lesions, is attributed to the slow development of the lesions. The growth rate of adenomas is $\sim$ 3 to $4 \%$ per year, which indicates low chances of developing significantly during the recommended screening interval.

Nonetheless, if a polyp is found and if it is impossible to exclude a potential malignancy during CT colonography, conventional colonoscopy must be performed for histopathological analysis and to determine the best treatment strategy. ${ }^{21}$ This process could be performed on the same day. Therefore, hospital centers with both radiological and endoscopic departments could guarantee full patient evaluation.

This study has limitations. The number of studies included in our metanalysis is small, which could be because we use only two databases and only one database provided articles that met our eligibility criteria. In addition, our restriction to include only articles in Portuguese and English prevented us from including relevant studies in other languages. Finally, during the development of our metanalysis, we noticed that most studies opted for unspecific or poorly defined eligibility criteria, which resulted in the exclusion of numerous articles.

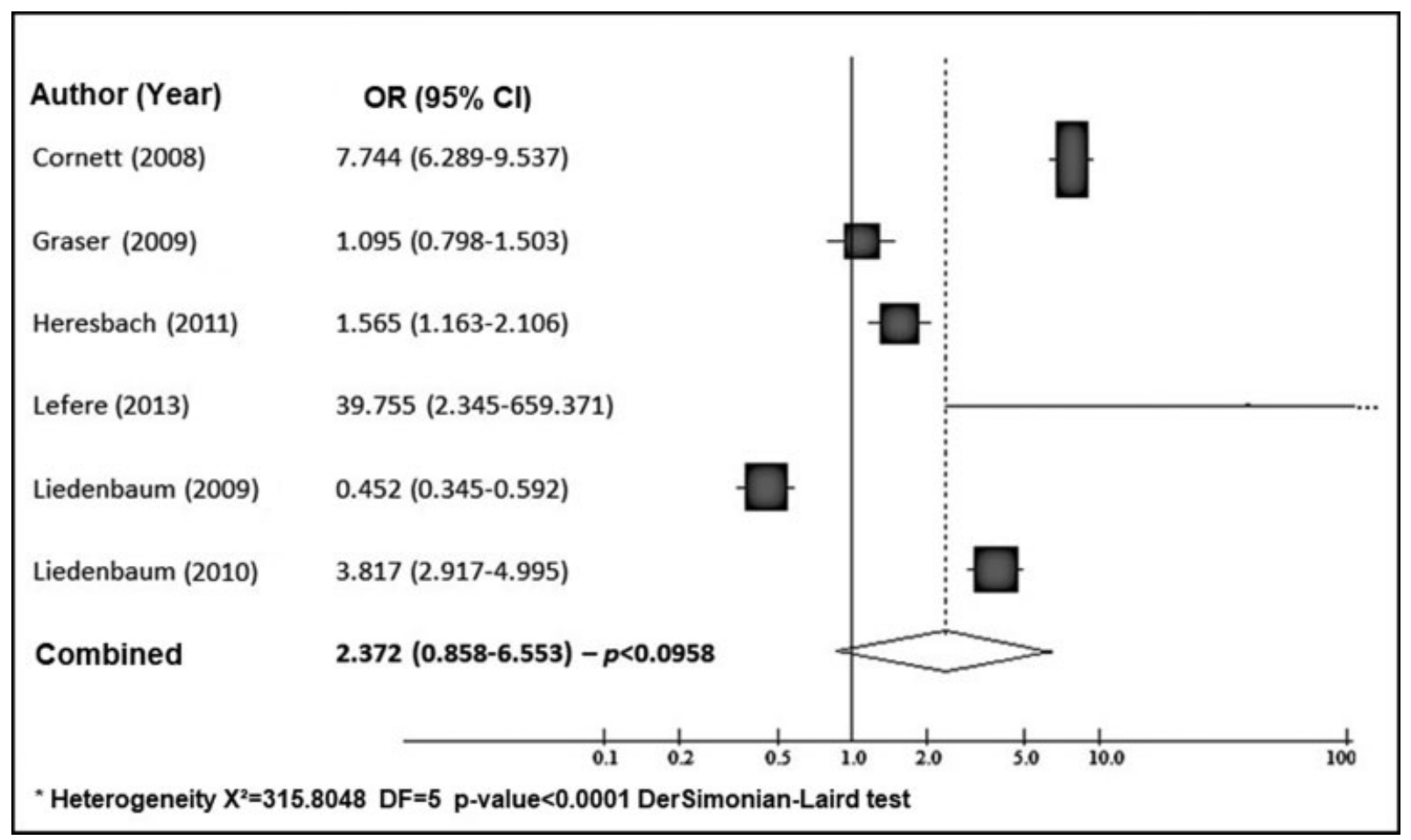

Fig. 3 Forest plot showing the odds ratios (OR) and 95\% confidence intervals of each study and of the studies combined for the sensitivity of virtual colonoscopy. 
Table 4 Calculation of the odds ratio, 95\% confidence interval, and weight of each study and of the studies combined for the specificity of virtual colonoscopy grouped by lesion size

\begin{tabular}{|l|l|l|l|l|l|l|l|}
\hline \multirow{2}{*}{ Author } & \multirow{2}{*}{ Year } & Specificity & \multirow{2}{*}{ OR } & \multicolumn{2}{l|}{ 95\% CI } & Weight \\
\cline { 3 - 4 } & & $\leq \mathbf{9 m m}$ & $\mathbf{9 m m}$ & & Lower & Upper & \\
\hline Graser & 2008 & 91.3 & 92.0 & 3.455 & 2.103 & 5.677 & 15.58 \\
\hline Liedenbaum & 2009 & 91.0 & 82.0 & 2.760 & 2.208 & 3.450 & 77.04 \\
\hline Heresbach & 2011 & 88.0 & 92.0 & 3.198 & 2.095 & 4.882 & 21.47 \\
\hline Lefere & 2013 & 98.1 & 100.0 & 5.106 & 3.088 & 8.444 & 15.18 \\
\hline Combined & & $\mathbf{9 2 . 1}$ & $\mathbf{9 1 . 5}$ & $\mathbf{3 . 1 7 1}$ & $\mathbf{2 . 6 7 1}$ & $\mathbf{3 . 7 6 5}$ & $\boldsymbol{P}<\mathbf{0 . 0 0 0 1}$ \\
\hline
\end{tabular}

Abbreviations: $\mathrm{Cl}$, confidence interval; OR, odds ratio.

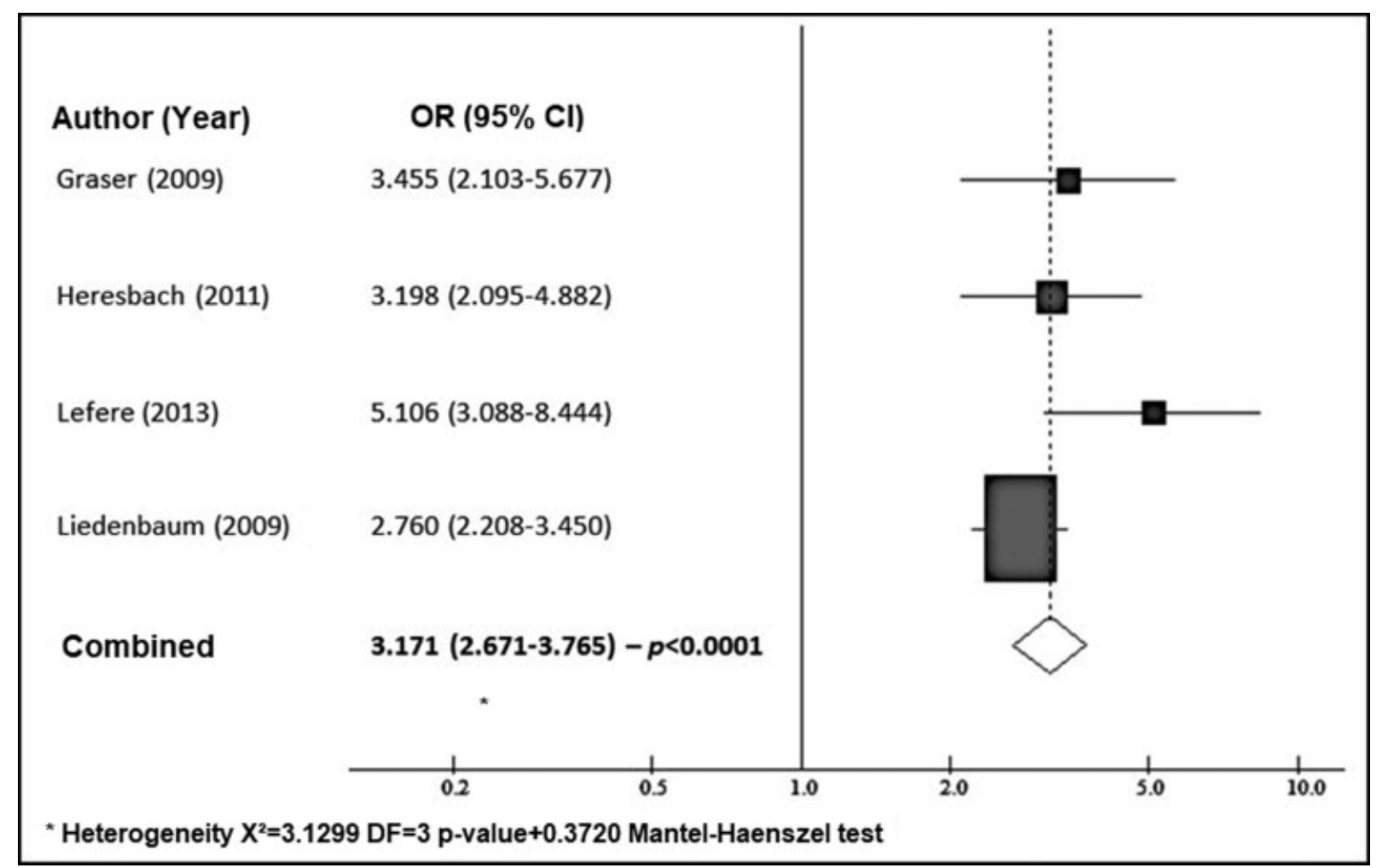

Fig. 4 Forest plot showing the odds ratios and 95\% confidence intervals of each study and of the studies combined for the specificity of virtual colonoscopy.

\section{Conclusion}

The present metanalysis reports the sensitivity and specificity of CT colonography in the detection of colorectal polyps. Overall, CT colonography has a sensitivity and specificity of $76.7 \%$ and $73.3 \%$, respectively. In addition, the specificity is higher for lesions $>9 \mathrm{~mm}$. Therefore, CT colonography has better specificity for larger lesions.

Most of the studies analyzed in our study were conducted before 2010, which is about a decade after the development of the technique using CT colonography and in agreement with the period in which CT colonography started being indicated as a screening method by the European and American guidelines. Therefore, further studies aimed at analyzing the technique after further technological advancements are warranted, which could lead to the development of more modern devices.

\section{Highlights}

- Virtual colonoscopy has better specificity for larger lesions.

- Virtual colonoscopy has become a viable alternative to conventional colonoscopy.

- The sensitivity of virtual colonoscopy is similar to that of conventional colonoscopy.

Conflict of Interests

The authors have no conflict of interests to declare 


\section{References}

1 Stewart BW, Wild CP, Eds. World Cancer Report. IARC; 2014https://www.who.int/cancer/publications/WRC_2014/en/. [accessed 05 March 2019]

2 Instituto Nacional de Câncer José Alencar Gomes da Silva - INCA. Estimativa da incidência e mortalidade por câncer no Brasil 2018. Rio de Janeiro2018http://www1.inca.gov.br/estimativa/2018/index.asp [accessed 05 March 2019]

3 Islami F, Goding Sauer A, Miller KD, et al. Proportion and number of cancer cases and deaths attributable to potentially modifiable risk factors in the United States. CA Cancer J Clin 2018;68(01): 31-54

4 American Cancer Society. Cancer facts \& figures 2017. Atlanta2017https://www.cancer.-

org/content/dam/cancer-org/research/cancer-facts-and-statistics/annual-cancer-facts-and-figures/2017/cancer-facts-and-figures-2017.pdf. [accessed 05 March 2019]

5 Rex DK, Boland CR, Dominitz JA, et al. Colorectal cancer screening: recommendations for physicians and patients from the U.S. multi-society task force on colorectal cancer. Gastroenterology 2017;153(01):307-323

6 Wolf AMD, Fontham ETH, Church TR, et al. Colorectal cancer screening for average-risk adults: 2018 guideline update from the American Cancer Society. CA Cancer J Clin 2018;68(04):250-281

7 Böhning D, Malzahn U, Dietz E, Schlattmann P, Viwatwongkasem C, Biggeri A. Some general points in estimating heterogeneity variance with the DerSimonian-Laird estimator. Biostatistics 2002;3(04):445-457

8 Higgins JPT, White IR, Wood AM. Imputation methods for missing outcome data in meta-analysis of clinical trials. Clin Trials 2008;5 (03):225-239

9 Henmi M, Copas JB. Confidence intervals for random effects metaanalysis and robustness to publication bias. Stat Med 2010;29 (29):2969-2983

10 Berman NG, Parker RA. Meta-analysis: neither quick nor easy. BMC Med Res Methodol 2002;2:10

11 Silva ACS, da Veiga JB, da Veiga BB, Caioni C, de Oliveira AS. Avaliação do software BioEstat para o ensino de estatística nos cursos de graduação. Rev Univ Vale Rio Verde 2014;12:375-385
12 Cornett D, Barancin C, Roeder B, et al. Findings on optical colonoscopy after positive CT colonography exam. Am J Gastroenterol 2008;103(08):2068-2074

13 Graser A, Stieber P, Nagel D, et al. Comparison of CT colonography, colonoscopy, sigmoidoscopy and faecal occult blood tests for the detection of advanced adenoma in an average risk population. Gut 2009;58(02):241-248

14 Sali L, Falchini M, Della Monica P, et al. CT colonography before colonoscopy in subjects with positive faecal occult blood test. Preliminary experience. Radiol Med (Torino) 2010;115(08): 1267-1278

15 Liedenbaum MH, van Rijn AF, de Vries AH, et al. Using CT colonography as a triage technique after a positive faecal occult blood test in colorectal cancer screening. Gut 2009;58(09): 1242-1249

16 Liedenbaum MH, de Vries AH, van Rijn AF, et al. CT colonography with limited bowel preparation for the detection of colorectal neoplasia in an FOBT positive screening population. Abdom Imaging 2010;35(06):661-668

17 Heresbach D, Djabbari M, Riou F, et al. Accuracy of computed tomographic colonography in a nationwide multicentre trial, and its relation to radiologist expertise. Gut 2011;60(05): 658-665

18 Lefere P, Silva C, Gryspeerdt S, et al. Teleradiology based CT colonography to screen a population group of a remote island; at average risk for colorectal cancer. Eur J Radiol 2013;82(06): e262-e267

19 von Atzingen AC, Tiferes DA, Deak E, Matos D, D'Ippolito G. Using computed tomography colonography in patients at high risk of colorectal cancer - a prospective study in a university hospital in South America. Clinics (São Paulo) 2014;69(11):723-730

20 Plumb AA, Halligan S, Pendsé DA, Taylor SA, Mallett S. Sensitivity and specificity of CT colonography for the detection of colonic neoplasia after positive faecal occult blood testing: systematic review and meta-analysis. Eur Radiol 2014;24(05): 1049-1058

21 Simon K. Colorectal cancer development and advances in screening. Clin Interv Aging 2016;11:967-976 